OPEN ACCESS

Edited by:

Francis Degache,

University of Applied Sciences and Arts of Western Switzerland,

Switzerland

Reviewed by:

Beat Knechtle

University Hospital Zurich, Switzerland Chuanye Huang,

Shandong Sport University, China

${ }^{*}$ Correspondence: Volker Scheer

volkerscheer@yahoo.com

Specialty section:

This article was submitted to

Exercise Physiology,

a section of the journal

Frontiers in Physiology

Received: 22 September 2018 Accepted: 30 November 2018 Published: 13 December 2018

Citation:

Scheer V, Vieluf S, Cramer L, Jakobsmeyer $\mathrm{R}$ and Heitkamp $\mathrm{H}-\mathrm{C}$ (2018) Changes in Running Economy

During a 65-km Ultramarathon.

Front. Physiol. 9:1809.

doi: 10.3389/fphys.2018.01809

\section{Changes in Running Economy During a 65-km Ultramarathon}

\author{
Volker Scheer ${ }^{1,2 *}$, Solveig Vieluf², Leoni Cramer², Rasmus Jakobsmeyer ${ }^{2}$ and \\ Hans-Christian Heitkamp ${ }^{2}$
}

${ }^{1}$ Ultra Sports Science Foundation, Pierre-Bénite, France, ${ }^{2}$ Department of Exercise and Health, Institute of Sports Medicine, Paderborn University, Paderborn, Germany

Purpose: Running economy (RE), expressed as oxygen cost $\left(\mathrm{O}_{2}\right.$ cost) and energy cost of running $(\mathrm{Cr})$ is important in ultramarathon (UM) running as it can help predict race performance. Controversy remains if RE increases, decreases, or remains stable in UM running. We examined RE before, during, and after a 65-km UM.

Methods: 15 male UM runners (mean age $45 \pm 5.7$ years) completed a standard exercise test (mean $\mathrm{VO}_{2} \max 48.8 \pm 3.4 \mathrm{ml} \cdot \mathrm{kg}^{-1} \cdot \mathrm{min}^{-1}$ ) for determination of the individual testing speed $\left(60 \% \mathrm{VO}_{2}\right.$ max: mean speed $\left.9.4 \pm 0.7 \mathrm{~km} / \mathrm{h}\right)$. This was followed by a $65-\mathrm{km}$ UM (elevation $\pm 1093 \mathrm{~m}$ ) consisting of three laps (each $21.7 \mathrm{~km}$ ). Pre and post indirect calorimetry measurements at individual running speed on the treadmill at UM-specific slopes (average percentage of positive and negative elevation) at $-3,+3 \%$, and level grade were performed in randomized order on a motorized treadmill in the laboratory for calculation of RE. Additionally after each lap, testing at $+3 \%$ took place.

Results: The $\mathrm{O}_{2}$ cost, $\mathrm{Cr}$, and RER increased significantly pre to post UM ( $p<0.01$ ). During the uphill running, a main effect of distance indicated a gradual, linear increase in $\mathrm{O}_{2}$ cost, $F(2,28)=5.81, p<0.01, \eta_{p}^{2}=0.29$, and $\mathrm{Cr}, F(2,28)=5.96, p=0.01$, $\eta_{p}^{2}=0.30$.

Conclusion: $\mathrm{O}_{2}$ cost and $\mathrm{Cr}$ increased significantly pre to post UM in all testing conditions as well as during the uphill testing throughout the UM. This is the first study to demonstrate a consistent increase in $\mathrm{O}_{2}$ cost and $\mathrm{Cr}$ among a range of different slopes, at individual running speeds and race-specific slopes giving further evidence that these measures of RE increase in UM running.

Keywords: oxygen consumption, physiology, endurance, energy cost of running, oxygen cost of running

\section{INTRODUCTION}

Popularity in ultramarathon (UM) running has increased over the years and includes race distances in excess of the traditional marathon distance of $42.195 \mathrm{~km}$ (Scheer, 2018). They are often held in challenging environmental conditions, testing the limits of human endurance (Scheer et al., 2015). Considerable research has focused on the medical and physiological aspects of UMs (Millet et al., 2000, 2011a; Scheer and Murray, 2011; Millet and Millet, 2012; Costa et al., 2013; Hoffman et al., 2014; Scheer et al., 2014; Vernillo et al., 2017a), but up to now, controversy remains on the role of running economy (RE) in UM running (Vernillo et al., 2017b). RE is important as it is classically 
used in conjunction with $\mathrm{VO}_{2} \max$ and percentage of $\mathrm{VO}_{2} \max$ to predict race performance (Barnes and Kilding, 2015; Scheer et al., 2018a). RE is a multifactorial concept that combines the function of the metabolic, cardiopulmonary, biomechanical, and neuromuscular system (Barnes and Kilding, 2015) and can either be expressed as oxygen consumption (in $\mathrm{ml} \cdot \mathrm{kg}^{-1} \cdot \mathrm{min}^{-1}$ ), oxygen consumption to cover a given distance [oxygen cost $\left(\mathrm{O}_{2}\right.$ cost $)$, e.g., in $\left.\mathrm{ml} \mathrm{O}_{2} \cdot \mathrm{kg}^{-1} \cdot \mathrm{km}^{-1}\right]$ or as the energy cost of running $(\mathrm{Cr})$ expressed in units of energy $\left(\mathrm{J} \cdot \mathrm{kg}^{-1} \cdot \mathrm{m}^{-1}\right.$ ) (Fletcher et al., 2009; Barnes and Kilding, 2015; Vernillo et al., 2015, 2017a). Cr is of particular interest in UM as it reflects the energy demand in prolonged exercise where a shift from carbohydrate to fat substrate utilization can be observed (Schena et al., 2014; Vernillo et al., 2015, 2017a). Cr typically increases up to marathon distances (Brueckner et al., 1991), but in UM, there is debate if $\mathrm{Cr}$ really increases after an UM (Vernillo et al., 2017b) as some studies suggest (Gimenez et al., 2013; Vernillo et al., 2015), remains stable (Schena et al., 2014; Vernillo et al., 2014, 2015; Balducci et al., 2017; Savoldelli et al., 2017), or decrease post UM (Vernillo et al., 2014, 2016). Data pertaining the $\mathrm{O}_{2}$ cost of running are more uniform, with the majority of studies demonstrating an increase (Lazzer et al., 2012, 2015; Schena et al., 2014) or no change post UM (Millet et al., 2000, 2009; Fusi et al., 2008; Lazzer et al., 2014; Balducci et al., 2017). Most studies have investigated RE changes pre to post UM (Vernillo et al., 2014, 2016; Lazzer et al., 2015; Balducci et al., 2017) but only one study to date (Schena et al., 2014) investigated RE during a 60-km UM in field conditions that found no significant changes in $\mathrm{Cr}$. Some of those discrepancies observed may be due to methodological differences in study designs (Vernillo et al., 2017b). It has recently been suggested that future studies should take into consideration the specific UM race characteristics and profile and use individual testing speeds and race-specific gradients for RE testing on the treadmill after sufficient familiarization with testing conditions (Vernillo et al., 2017b).

The purpose of our study was to investigate $\mathrm{RE}\left(\mathrm{Cr}\right.$ and $\mathrm{O}_{2}$ cost) before, during, and after a 65-km UM, addressing some of those methodological concerns raised and examining runners at individual running speeds and different specific gradient slopes (level, uphill, and downhill) on the treadmill according to the specific UM profile. Our hypothesis was that $\mathrm{Cr}$ and $\mathrm{O}_{2}$ cost would increase with increasing running distance and among different gradients.

\section{MATERIALS AND METHODS}

\section{Participants}

Fifteen experienced male UM runners (age $44.9 \pm 5.7$ years, height $178.3 \pm 4.9 \mathrm{~cm}$, weight $78.4 \pm 8.4 \mathrm{~kg}$, BMI $24.6 \pm 2.2 \mathrm{~kg} / \mathrm{m}^{2}$, running experience $12.2 \pm 8.6$ years, previous UM experience $5 \pm 4.2$ races, training kilometers per week $75 \pm 19.3 \mathrm{~km}$ ) volunteered to participate in the study. Only healthy male athletes, between the ages of 18 and 60 years, who previously participated in at least one UM of more than $60 \mathrm{~km}$, were allowed to participate. Runners who had sustained a recent injury (less than 3 months before the event) were excluded.
They were recruited through announcements at local running clubs and local Internet groups for runners. All participants were informed of the protocol prior to the first test and provided written, informed consent. The internal review board of the local medical council (Ärztekammer Westfalen-Lippe) and the University of Münster, Germany, approved all procedures (approval number 2017-465-f-S), and research was conducted in accordance with the Declaration of Helsinki.

\section{Study Design}

The study design consisted of two test days. Participants were instructed to abstain from consuming alcohol or caffeine and refrain from strenuous and exhaustive exercise $24 \mathrm{~h}$ prior to each test day. On test day 1 , participants received a medical checkup, consisting of medical history and examination of the musculoskeletal and cardiovascular system, resting blood pressure (Adult 11, durable blood pressure cuff, Welch Allyn, Skaneateles, NY, United States) and resting ECG (Cardio 100 BT, Custo, Ottobrunn, Germany) by the attending physician to exclude any significant underlying pathologies. All participants were attested to be in good health and able to participate in the study. Participants were familiar with treadmill running and were further familiarized with the specific running protocol on the treadmill (h/p/cosmos Pulsar 3p; Traunstein, Germany). This was followed by a standard graded exercise test (starting at $6.0 \mathrm{~km} / \mathrm{h}$, step duration $3 \mathrm{~min}$, increased by $2.0 \mathrm{~km} / \mathrm{h}$, and inclination $1.0 \%$ ) until task failure with continuous breath by breath measurements for ventilatory parameters (Metalyzer 3B, Cortex Biophysik, Leipzig, Germany) (Scheer et al., 2018b). To determine individual running speed for treadmill tests on test day 2 , the speed at $60 \%$ $\mathrm{VO}_{2}$ max was extrapolated from the $\mathrm{VO}_{2}$-work rate relationship. This intensity was selected as it corresponds to intensities observed during 6-h events (Davies and Thompson, 1979).

\section{Ultramarathon}

Test day 2 included four running tests on the treadmill, two venous blood samples, and a $65-\mathrm{km}$ UM. Test day 2 was conducted on three separate occasions due to limitations of equipment and staff capacity, to ensure smooth testing procedures with little to no waiting times (maximum number of six participants per day). For the same reason, RE measurements during the UM could only be conducted at $+3 \%$ incline. Tests took place in January and February 2018 with comparable outdoor conditions (average temperature $+6^{\circ} \mathrm{C}$ ) for the UM. The UM was designed as a loop course (a total of three laps) starting and finishing at our university department. Each lap measured $21.7 \mathrm{~km}$ with a cumulative ascent of $364.4 \mathrm{~m}$ and cumulative descent of $364.4 \mathrm{~m}$ (Garmin Forerunner 735XT), equating to a total distance of $65 \mathrm{~km}( \pm 1093 \mathrm{~m})$. The terrain consisted predominately of forest tracks, gravel, and tarmac paths. It contained several uphill and downhill running sections and the average slope measured 3\% (positive and negative elevation), which was used as the incline/decline for further tests (uphill/downhill) on the treadmill as outlined below. Participants were allowed to select their own individual running speed during the UM and were allowed to drink and eat ad libitum. During the 
course, runners were self-sufficient but after each lab food and drink was provided to them at the university.

\section{Running Economy}

Treadmill tests (A-D) were standardized and included continuous measurements of ventilatory parameters including oxygen uptake $\left(\dot{\mathrm{V}}_{2}\right)$, carbon dioxide output $\left(\mathrm{V}^{\mathrm{V}} \mathrm{O}_{2}\right)$, and respiratory exchange ratio (RER) after calibration before each test (Scheer et al., 2018b). Heart rate values were obtained via Bluetooth (Polar T31 sensor) and participants were asked to provide rate of perceived exertion (RPE) on the 6- to 20-point Borg scale immediately prior and at the end of each test (Borg, 1985). Test A (just before the start of the UM) and test D (immediately after the finish of the UM) were conducted in the

TABLE 1 | Descriptive results [mean values and standard deviation (SD)] from the initial exercise test, blood parameters and RPE pre and post UM, with relative change and correlation to $\mathrm{O}_{2}$ cost and $\mathrm{Cr}$.

\begin{tabular}{|c|c|c|c|c|c|c|c|}
\hline & & Pre & Post & Relative change & & Correlation with $\mathrm{O}_{2}$ cost & Correlation with $\mathrm{Cr}$ \\
\hline $\mathrm{VVO}_{2} \max (\mathrm{km} / \mathrm{h})$ & Mean (SD) & $16.22(1.00)$ & & & & & \\
\hline Leukocytes $\left(10^{9} / \mathrm{L}\right)$ & Mean (SD) & $5.58(1.62)$ & $14.75(3.20)$ & $174.84 *(68.32)$ & $r(p)$ & $-0.37(0.17)$ & $-0.38(0.17)$ \\
\hline CK (U/L) & Mean (SD) & $172.27(71.79)$ & $681.53(393.64)$ & $311.29 *(178.09)$ & $r(p)$ & $0.31(0.27)$ & $0.29(0.29)$ \\
\hline $\mathrm{CRP}(\mathrm{mg} / \mathrm{L})$ & Mean (SD) & $0.09(0.06)$ & $0.17(0.13)$ & $113.49(98.61)$ & $r(p)$ & $0.31(0.26)$ & $0.30(0.27)$ \\
\hline
\end{tabular}

*Indicates that one-sample tests reached significance with Bonferroni correction.

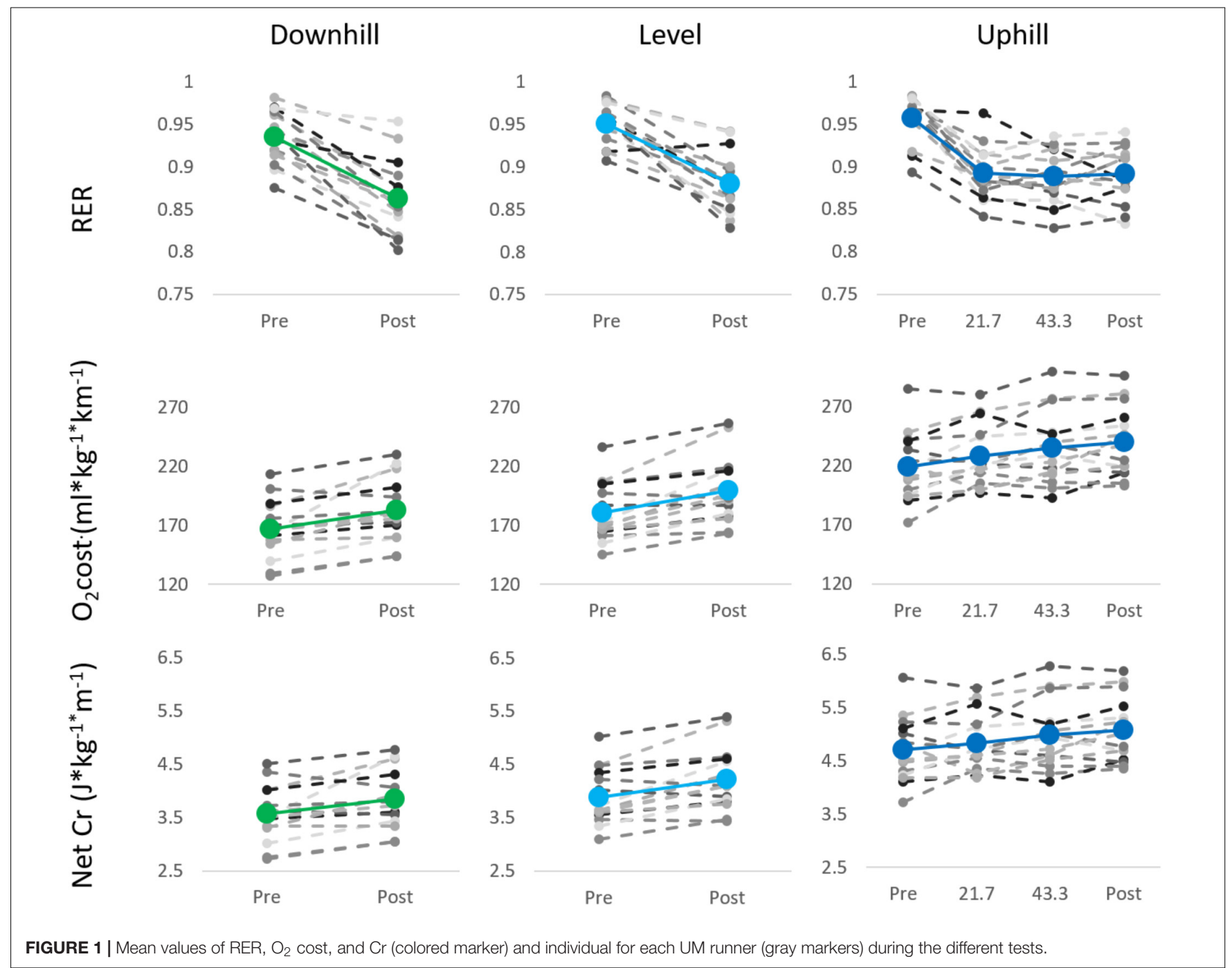


same fashion and consisted of three 5-min running intervals on the treadmill at $60 \% \mathrm{VO}_{2}$ max of the individual running speed in randomized order at level grade, $+3 \%$ incline, and $-3 \%$ decline, with a one minute rest period between intervals. Test $\mathrm{B}$ (after one lap of running) and Test $\mathrm{C}$ (after two laps of running) where conducted in the same fashion but only at $+3 \%$ incline of the treadmill. To calculate RE, $\dot{\mathrm{VO}} 2, \dot{\mathrm{V}} \mathrm{CO}_{2}$, and RER were obtained from the last minute of treadmill running during steady state conditions and were filtered into 5-s blocks for data analyses as described by Vernillo et al. (2015). Net $\mathrm{VO}_{2}$ values were obtained from calculating the difference of $\mathrm{VO}_{2}$ at steady state minus $\mathrm{VO}_{2}$ at rest and for determination of the caloric equivalent of $\dot{V}_{2}$ values were converted depending on RER values (Péronnet and Massicotte, 1991). RE was expressed as both net $\mathrm{O}_{2}$ cost of running $\left(\mathrm{O}_{2} \cdot \mathrm{kg}^{-1} \cdot \mathrm{km}^{-1}\right)$ and net $\mathrm{Cr}$ of running $(\mathrm{Cr}$ in $\left.\mathrm{J} \cdot \mathrm{kg}^{-1} \cdot \mathrm{m}^{-1}\right)$ (Vernillo et al., 2015).

\section{Blood Sampling}

Venous blood samples were obtained immediately prior and post UM in resting supine position from the antecubital vein by the attending physician. Blood parameters obtained included creatine kinase (CK), C-reactive protein (CRP), and leucocyte count.

\section{Statistical Analyses}

Statistical analyses were conducted in SPSS for Windows version 20.0 (IBM Corp., Armonk, NY, United States). The relative change $[$ relative change $=($ post - pre $) /$ pre $\times 100$ ] was expressed as the difference between pre and post measure in relation to pretest values in per cent and was calculated for RER, $\mathrm{O}_{2}$ cost and Cr. Rate of change was tested with one-sample tests. Standard significance level was set to $p<0.05$ and corrected for multiple comparisons by Bonferroni correction $\left(\alpha^{\prime}=0.05 / 5=0.01\right)$. To test for differences between tests, repeated measure ANOVA with three tests (downhill, level, and uphill) was calculated for the relative change of RER, $\mathrm{O}_{2}$ cost, and $\mathrm{Cr}$. To analyze changes continuously during the uphill test, $\mathrm{RER}, \mathrm{O}_{2}$ cost, and $\mathrm{Cr}$ changes in relation to pretest measures were analyzed with a repeated measure ANOVA with the factor three distance $(21.7,43.4$, and $65 \mathrm{~km}$ ). Greenhouse-Geisser adjustment was reported in case the sphericity assumption was violated. Effect sizes were reported as partial eta squares $\left(\eta_{\mathrm{p}}^{2}\right)$. Post hoc tests were corrected with Bonferroni. $p$-Values were corrected by SPSS. Based on violation of normal distribution, we calculated Spearman correlations between the relative changes of RER, $\mathrm{O}_{2}$ cost, $\mathrm{Cr}$ and the blood parameters as well as the numerical values of the RPE.

\section{RESULTS}

The values from the initial exercise test, pre and post UM blood parameters, and values of the RPE with their relative change and correlation to $\mathrm{O}_{2}$ cost and $\mathrm{Cr}$ are shown in Table 1. All blood markers and the RPE increased significantly pre to post UM, but their relative changes did neither correlate with $\mathrm{O}_{2}$ cost nor $\mathrm{Cr}$ apart from RPE values. Absolute mean values $( \pm \mathrm{SD})$ were the following for RER, $\mathrm{O}_{2}$ cost, and $\mathrm{Cr}$ pre vs. post for level $(0.95 \pm 0.02$ vs. $0.88 \pm 0.04,180.60 \pm 24.75$ vs. $199.47 \pm 28.43$ $\mathrm{O}_{2} \cdot \mathrm{kg}^{-1} \cdot \mathrm{km}^{-1}$, and $3.88 \pm 0.52$ vs. $\left.4.22 \pm 0.59 \mathrm{~J} \cdot \mathrm{kg}^{-1} \cdot \mathrm{m}^{-1}\right)$ and downhill running $(0.94 \pm 0.03$ vs. $0.86 \pm 0.04,166.60 \pm 24.25$ vs. $182.40 \pm 26.58 \mathrm{O}_{2} \cdot \mathrm{kg}^{-1} \cdot \mathrm{km}^{-1}$, and $3.57 \pm 0.52$ vs. $\left.3.85 \pm 0.55 \mathrm{~J} \cdot \mathrm{kg}^{-1} \cdot \mathrm{m}^{-1}\right)$. During the four different time points in uphill running $\mathrm{RER}, \mathrm{O}_{2}$ cost, and $\mathrm{Cr}$ were as follows: $0.96 \pm 0.03$ vs. $0.89 \pm 0.03$ vs. $0.89 \pm 0.03$ vs. $0.89 \pm 0.03,218.87 \pm 28.29$ vs. $227.93 \pm 30.45$ vs. $234.93 \pm 30.63$ vs. $239.93 \pm 29.17$ $\mathrm{O}_{2} \cdot \mathrm{kg}^{-1} \cdot \mathrm{km}^{-1}$, and $4.71 \pm 0.59$ vs. $4.83 \pm 0.54$ vs. $4.98 \pm 0.63$ vs. $5.08 \pm 0.60 \mathrm{~J} \cdot \mathrm{kg}^{-1} \cdot \mathrm{m}^{-1}$. Graphical presentation of the mean values and data of each individual runner for RER, $\mathrm{O}_{2}$ cost, and $\mathrm{Cr}$ for downhill, level, and uphill running at the different time points can be seen in Figure 1. Calculated relative changes are presented in Table 2. Relative changes for RER showed changes through all pre to post-tests during level and downhill running and all subsequent measures during uphill running. This was also observed with $\mathrm{O}_{2}$ cost and $\mathrm{Cr}$ during level and downhill running and after $21.7 \mathrm{~km}$ and subsequent tests in uphill running (see Table 2). All protocols showed significant relative changes from pre to post test, as indicated by significant one sample $t$-test

TABLE 2 | Mean values and standard deviations (SD) as well as results of one-sample tests ( $d f=14$ and * indicates significance after Bonferroni correction) relative changes per group for all measures in the three different tests and distances.

\begin{tabular}{|c|c|c|c|c|}
\hline & & RER & $\mathrm{O}_{2}$ cost & $\mathrm{Cr}$ \\
\hline Post UM & Mean (SD) & $-7.40(3.88)$ & $10.66(8.33)$ & 8.98 (8.04) \\
\hline \multicolumn{5}{|l|}{ Downhill } \\
\hline \multirow[t]{2}{*}{ Post UM } & Mean (SD) & $-7.74(3.55)$ & $9.86(9.39)$ & $8.34(9.47)$ \\
\hline & $T ; p$ & $-8.44 ;<0.01^{*}$ & $4.07 ;<0.01 *$ & $3.41 ;<0.01^{*}$ \\
\hline \multirow[t]{2}{*}{$21.7 \mathrm{~km}$} & Mean (SD) & $-6.81(2.81)$ & $4.56(7.40)$ & $2.90(7.47)$ \\
\hline & $T ; p$ & $-9.37 ;<0.01^{*}$ & $2.39 ; 0.03$ & $1.50 ; 0.15$ \\
\hline \multirow[t]{2}{*}{$43.4 \mathrm{~km}$} & Mean (SD) & $-7.19(2.37)$ & $7.58(7.40)$ & $5.98(7.28)$ \\
\hline & $T ; p$ & $-11.77 ;<0.01^{*}$ & $3.97 ;<0.01^{*}$ & $3.18 ;<0.01^{*}$ \\
\hline \multirow[t]{2}{*}{ Post UM } & Mean (SD) & $-6.91(2.86)$ & $9.97(7.45)$ & $8.34(7.53)$ \\
\hline & $\mathrm{T} ; p$ & $-9.35 ;<0.01^{*}$ & $5.19 ;<0.01^{*}$ & $4.29 ;<0.01^{*}$ \\
\hline
\end{tabular}


for the parameters RER, $\mathrm{O}_{2}$, and $\mathrm{Cr}$ (see Table 2). Comparing the relative changes across protocols, repeated measure ANOVA revealed no main effect of protocol for RER, $F(2,28)=0.55$, $p=0.58, \eta_{\mathrm{p}}^{2}=0.04, \mathrm{O}_{2}$ cost $, F(2,28)=0.11, p=0.83, \eta_{\mathrm{p}}^{2}=0.01$, and $\mathrm{Cr}, F(2,28)=0.08, p=0.86, \eta_{\mathrm{p}}^{2}=0.01$. In addition to pre and post measures, the uphill test was conducted after 21.7 and $43.4 \mathrm{~km}$, to illustrate the progression of change. Analysis revealed no main effect of distance for RER, $F(2,28)=0.20, p=0.82$, $\eta_{\mathrm{p}}^{2}=0.01$. For both measures of RE, $\mathrm{O}_{2}$ cost, $F(2,28)=5.81$, $p<0.01, \eta_{\mathrm{p}}^{2}=0.29$, and Cr, $F(2,28)=5.96, p=0.01, \eta_{\mathrm{p}}^{2}=0.30$, a significant main effect of distance was revealed. Bonferroni corrected post hoc comparisons showed $\mathrm{O}_{2} \operatorname{cost}(p=0.04)$ and $\mathrm{Cr}(p=0.03)$ increased more at post-test than after $21.7 \mathrm{~km}$.

\section{DISCUSSION}

Our main findings are that $\mathrm{Cr}$ and $\mathrm{O}_{2}$ cost increased significantly pre to post UM in all testing conditions as well as during the uphill testing throughout the UM. This is in line with our hypothesis demonstrating a consistent increase in these measures of RE.

\section{$\mathrm{O}_{2}$ Cost of Running}

Oxygen cost of running increased by about $10 \%$ for uphill and downhill and about $11 \%$ for level grade running conditions pre to post UM. This is in line with most previous studies that showed an increase in the $\mathrm{O}_{2}$ cost of running post UM (Lazzer et al., 2012, 2015; Schena et al., 2014). A new finding is that during the UM in the uphill running conditions a significant gradual linear increase was observed at the different time points.

\section{RER and Energy Cost of Running}

However, it is also known that the $\mathrm{O}_{2}$ cost of running, especially in UM running can be overestimated and an expression of RE as $\mathrm{Cr}$ is a much better way of describing $\mathrm{RE}$ as it takes into account the caloric equivalent of $\mathrm{VO}_{2}$ (Péronnet and Massicotte, 1991; Vernillo et al., 2017b). RER values are therefore important, and it is known that they decrease over time with exercise especially post UM (Schena et al., 2014; Vernillo et al., 2015), in line with our own result. In prolonged exercise, a progressive depletion of glycogen stores occur with a shift in substrate utilization from carbohydrates to fat resulting in decreased RER values (Schena et al., 2014). Interestingly, that decrease was already observed after $21.7 \mathrm{~km}$, suggesting that the shift in substrate utilization had occurred at or before this time point.

Changes in RER values will have an obvious impact in calculating $\mathrm{Cr}$ when for the determination of the caloric equivalent $\mathrm{VO}_{2}$ values are converted depending on RER values (Péronnet and Massicotte, 1991). Cr has been shown to increase in running distances up to marathon (Brueckner et al., 1991), but in UM, there is still some debate if $\mathrm{Cr}$ increases (Gimenez et al., 2013; Vernillo et al., 2015), decrease (Vernillo et al., 2014, 2016) or remains stable after an UM (Fusi et al., 2008; Schena et al., 2014; Vernillo et al., 2014, 2015; Balducci et al., 2017; Savoldelli et al., 2017). Our results showed a significant increase in Cr across all testing conditions in downhill, level, and uphill running pre to post UM of between 8 and 9\%. Vernillo et al. (2015) reported a $13.1 \%$ increase in post-race $\mathrm{Cr}$ in downhill running conditions only with no differences in level or uphill Cr post UM over a similar distance of $65 \mathrm{~km}$ but with a much steeper elevation of $+4000 \mathrm{~m}$ and fixed treadmill testing conditions for participants regarding slope and speed $( \pm 5 \%$ and $10 \mathrm{~km} / \mathrm{h}$ ) (Vernillo et al., 2015). A new finding is that we also observed a significant gradual increase of $\mathrm{Cr}$ during uphill running conditions throughout the UM. To our knowledge, there is only one other study to date examining $\mathrm{Cr}$ changes during an $\mathrm{UM}$ in field conditions (Schena et al., 2014). A non-significant, but small gradual increase of $\mathrm{Cr}$ was observed, during a flat $60-\mathrm{km}$ UM course, with $\mathrm{Cr}$ measured at level grade running on a 400-m running track at selfselected speed equating to speeds of $65-70 \% \mathrm{VO}_{2} \max$ (Schena et al., 2014). Another study (Gimenez et al., 2013) examined RE during a $24-\mathrm{h}$ treadmill run, demonstrating an increase in oxygen consumption and concomitant decrease of RER in the first $8 \mathrm{~h}$, thus remaining stable thereafter. This resulted in an increased $\mathrm{Cr}$ during that time period (Gimenez et al., 2013) The mechanisms behind the increase in $\mathrm{Cr}$ after an UM are not fully understood but changes in the neuromuscular system and biomechanical factors seem to play an important role (Millet et al., 2011b; Degache et al., 2013; Vernillo et al., 2017b).

\section{Neuromuscular Factors and Fatigue}

Muscle fatigue and skeletal muscle damage can lead to changes in neural input to compensate decreasing muscle force especially during push off phase of the gait pattern (Millet et al., 2011b; Vernillo et al., 2017b). Biomechanical changes can alter gait pattern and increased stride frequency, and leg and tendon stiffness have been observed leading to compensatory adjustments in the gait pattern through the gait cycle (Millet et al., 2011b; Degache et al., 2013; Vernillo et al., 2015, 2017b). These changes require an increasing $\mathrm{VO}_{2}$ demand leading to increases in $\mathrm{Cr}$. For those studies that have shown an improvement in $\mathrm{Cr}$ post UM (Vernillo et al., 2014, 2016) the underlying mechanism are not clear either. Positive neuromuscular adaptations and control of fatigued muscles may lead to improvements in movement through redistribution from motor units of fatigued to non-fatigued muscle groups (Giandolini et al., 2016; Vernillo et al., 2017b). This may lead to a preservation of a more economical running pattern (Schena et al., 2014) which may be of importance in extreme UM that have been investigated over a distance of $330 \mathrm{~km}$ and $+24.000 \mathrm{~m}$ elevation (Vernillo et al., 2016) but this is not comparable to our current UM run.

Muscle enzyme (CK) and inflammatory markers (CRP and leukocytes) showed a significant increase from pre to post UM as described in previous studies (Schena et al., 2014; Gill et al., 2015). An increase of $\mathrm{Cr}$ with increasing muscle damage and raised CK have been observed (Kyröläinen et al., 2000); however, the correlation between muscle damage and changes in $\mathrm{Cr}$ are unclear (Schena et al., 2014) In our group, this increase was not correlated to and could not explain the rising $\mathrm{O}_{2}$ cost or $\mathrm{Cr}$, suggesting other mechanisms to be involved. This could be further substantiated by the increase of the RPE that correlated with the rising $\mathrm{O}_{2}$ cost and $\mathrm{Cr}$, demonstrating that fatigue or the 
subjective rating of effort and fatigue may play a role as previously suggested (Millet et al., 2011b; Gimenez et al., 2013).

\section{Methodological Considerations}

Methodological concerns may be an explanation of the discrepancies observed in $\mathrm{Cr}$ in the different studies. Race distances, race profiles, and race conditions have varied widely with races ranging from 43 to $330 \mathrm{~km}$ and 24,000 m elevations, to single case reports of a 8500-km expedition, making comparisons difficult (Millet et al., 2009; Lazzer et al., 2015; Vernillo et al., 2016, 2017a). Running speed and intensity have also varied widely ranging from speeds at $40-80 \%$ of $\mathrm{VO}_{2} \max$ (Lazzer et al., 2012; Vernillo et al., 2017b). Vernillo et al. (2017b) had therefore suggested to include specific testing conditions of the UM, assessing the consistency of the individual responses, providing adequate familiarizations sessions to participants to the specific protocol, and inserting a control group for future studies.

\section{Strength}

The main strength of the study is that we addressed some of the methodological considerations raised in the literature (Vernillo et al., 2017b). We included a preceding exercise test, to determine individual running speeds and participants received an adequate familiarization session of the testing protocol. The test protocol was designed according to specific slope conditions of the actual UM topography and tests were conducted not only pre- and postrace but also during the UM. Individual responses are presented in the results. However, we recognize that there are still some limitations and weaknesses to our study.

\section{Limitations}

Testing took place on a treadmill and outdoor running condition and surface differ; however recently, it has been shown that although subtle differences exist between overground and treadmill running, overground running can reasonably be replicated on the treadmill (Firminger et al., 2018). Outdoor testing in the field can be done with a mobile spirometry unit as has been demonstrated (Savoldelli et al., 2017); however, this may lead to other biases as for example testing speed and ambient conditions cannot be controlled as in laboratory conditions.

Other factors such as changes in running biomechanics can affect RE; however, we were not able to conduct kinematic analyses in this current study. Testing took place over three test days due to limitations in laboratory and staff capacity; however,

\section{REFERENCES}

Balducci, P., Clémençon, M., Trama, R., Blache, Y., and Hautier, C. (2017). Performance factors in a mountain ultramarathon. Int. J. Sports Med. 38, 819-826. doi: 10.1055/s-0043-112342

Barnes, K. R., and Kilding, A. E. (2015). Running economy: measurement, norms, and determining factors. Sports Med. Open 1:8. doi: 10.1186/s40798-015-0007-y

Borg, G. (1985). An Introduction to Borg's RPE-Scale. Available at: http://trove.nla. gov.au/version/45253441 [accessed December 1, 2017].

Brueckner, J. C., Atchou, G., Capelli, C., Duvallet, A., Barrault, D., Jousselin, E., et al. (1991). The energy cost of running increases with the distance covered. Eur. J. Appl. Physiol. Occup. Physiol. 62, 385-389. doi: 10.1007/BF00626607 ambient conditions at the three test days were comparable so this should not have had an impact on the results. The study was conducted as a simulated $65 \mathrm{~km}$ run and not under race conditions, so some participants may not have reached their full potential, but considering the distance covered and the time needed to complete that distance this should not have negatively impacted the results obtained.

\section{Future Considerations}

Examining changes in RE in the field, during different time points at varying UM distances and gradient slopes will be interesting, especially in groups of homogenous UM runners or elite UM runners. The insertion of a control group (Vernillo et al., 2017b) may also yield new insights.

\section{CONCLUSION}

Energy cost of running and $\mathrm{O}_{2}$ cost increased significantly pre to post UM in all testing conditions as well as during the uphill testing throughout the UM. This is the first study to demonstrate a consistent increase in these measures of $\mathrm{RE}$ among a range of different slopes, at individual running speeds and race-specific slopes giving further evidence that $\mathrm{Cr}$ and $\mathrm{O}_{2}$ cost indeed increase in UM running.

\section{AUTHOR CONTRIBUTIONS}

VS and $\mathrm{H}-\mathrm{CH}$ contributed substantially to the conception and design of this study. VS and LC contributed to data collection. SV carried out the data analysis and interpretation together with VS, LC, RJ, and H-CH. VS wrote the first draft of the manuscript, and all authors were involved in revising it critically. All authors gave final approval of the version to be published and agreed to be accountable for all aspects of this work.

\section{ACKNOWLEDGMENTS}

We thank Jennifer Ahmann, Laura Fassbender, Tanja Janssen, and Roman Gaidai in helping to collect data during this research project. We thank all ultramarathon runners for their participation in this study.

Costa, R. J. S., Teixeira, A., Rama, L., Swancott, A. J. M., Hardy, L. D., Lee, B., et al. (2013). Water and sodium intake habits and status of ultra-endurance runners during a multi-stage ultra-marathon conducted in a hot ambient environment: an observational field based study. Nutr. J. 12:13. doi: 10.1186/1475-2891$12-13$

Davies, C. T., and Thompson, M. W. (1979). Aerobic performance of female marathon and male ultramarathon athletes. Eur. J. Appl. Physiol. Occup. Physiol. 41, 233-245. doi: 10.1007/BF004 29740

Degache, F., Guex, K., Fourchet, F., Morin, J. B., Millet, G. P., Tomazin, K., et al. (2013). Changes in running mechanics and spring-mass behaviour induced by a 5-hour hilly running bout. J. Sports Sci. 31, 299-304. doi: 10.1080/02640414. 2012.729136 
Firminger, C. R., Vernillo, G., Savoldelli, A., Stefanyshyn, D. J., Millet, G. Y., and Edwards, W. B. (2018). Joint kinematics and ground reaction forces in overground versus treadmill graded running. Gait Posture 63, 109-113. doi: 10.1016/j.gaitpost.2018.04.042

Fletcher, J. R., Esau, S. P., and Macintosh, B. R. (2009). Economy of running: beyond the measurement of oxygen uptake. J. Appl. Physiol. 107, 1918-1922. doi: 10.1152/japplphysiol.00307.2009

Fusi, S., Salvadego, D., and Bresadola, V. (2008). Maximal oxygen consumption and energy cost of running after a long-lasting running race: the $100 \mathrm{~km}$ of Sahara. Sport Sci. Health 2:93. doi: 10.1007/s11332-008-0046-6

Giandolini, M., Vernillo, G., Samozino, P., Horvais, N., Edwards, W. B., Morin, J.B., et al. (2016). Fatigue associated with prolonged graded running. Eur. J. Appl. Physiol. 116, 1859-1873. doi: 10.1007/s00421-016-3437-4

Gill, S. K., Teixeira, A., Rama, L., Prestes, J., Rosado, F., Hankey, J., et al. (2015). Circulatory endotoxin concentration and cytokine profile in response to exertional-heat stress during a multi-stage ultra-marathon competition. Exerc. Immunol. Rev. 21, 114-128.

Gimenez, P., Kerhervé, H., Messonnier, L. A., Féasson, L., and Millet, G. Y. (2013). Changes in the energy cost of running during a 24-h treadmill exercise. Med. Sci. Sports Exerc. 45, 1807-1813. doi: 10.1249/MSS.0b013e318292c0ec

Hoffman, M. D., Pasternak, A., Rogers, I. R., Khodaee, M., Hill, J. C., Townes, D. A., et al. (2014). Medical services at ultra-endurance foot races in remote environments: medical issues and consensus guidelines. Sports Med. 44, 10551069. doi: 10.1007/s40279-014-0189-3

Kyröläinen, H., Pullinen, T., Candau, R., Avela, J., Huttunen, P., and Komi, P. V. (2000). Effects of marathon running on running economy and kinematics. Eur. J. Appl. Physiol. 82, 297-304. doi: 10.1007/s004210000219

Lazzer, S., Salvadego, D., Rejc, E., Buglione, A., Antonutto, G., and di Prampero, P. E. (2012). The energetics of ultra-endurance running. Eur. J. Appl. Physiol. 112, 1709-1715. doi: 10.1007/s00421-011-2120-z

Lazzer, S., Salvadego, D., Taboga, P., Rejc, E., Giovanelli, N., and di Prampero, P. E. (2015). Effects of the Etna uphill ultramarathon on energy cost and mechanics of running. Int. J. Sports Physiol. Perform. 10, 238-247. doi: 10.1123/ijspp.20140057

Lazzer, S., Taboga, P., Salvadego, D., Rejc, E., Simunic, B., Narici, M. V., et al. (2014). Factors affecting metabolic cost of transport during a multi-stage running race. J. Exp. Biol. 217, 787-795. doi: 10.1242/jeb.091645

Millet, G., Lepers, R., Lattier, G., Martin, V., Babault, N., and Maffiuletti, N. (2000). Influence of ultra-long-term fatigue on the oxygen cost of two types of locomotion. Eur. J. Appl. Physiol. 83, 376-380. doi: 10.1007/s004210000313

Millet, G. P., and Millet, G. Y. (2012). Ultramarathon is an outstanding model for the study of adaptive responses to extreme load and stress. BMC Med. 10:77. doi: 10.1186/1741-7015-10-77

Millet, G. Y., Banfi, J. C., Kerherve, H., Morin, J. B., Vincent, L., Estrade, C., et al. (2011a). Physiological and biological factors associated with a $24 \mathrm{~h}$ treadmill ultra-marathon performance. Scand. J. Med. Sci. Sports 21, 54-61. doi: 10.1111/ j.1600-0838.2009.01001.x

Millet, G. Y., Tomazin, K., Verges, S., Vincent, C., Bonnefoy, R., Boisson, R.-C., et al. (2011b). Neuromuscular consequences of an extreme mountain ultramarathon. PLoS One 6:e17059. doi: 10.1371/journal.pone.0017059

Millet, G. Y., Morin, J.-B., Degache, F., Edouard, P., Feasson, L., Verney, J., et al. (2009). Running from Paris to Beijing: biomechanical and physiological consequences. Eur. J. Appl. Physiol. 107, 731-738. doi: 10.1007/s00421-0091194-3

Péronnet, F., and Massicotte, D. (1991). Table of nonprotein respiratory quotient: an update. Can. J. Sport Sci. 16, 23-29.
Savoldelli, A., Fornasiero, A., Trabucchi, P., Limonta, E., La Torre, A., Degache, F., et al. (2017). The energetics during the world's most challenging mountain ultra-marathon-a case study at the Tor des Geants ${ }^{\circledR}$. Front. Physiol. 8:1003. doi: 10.3389/fphys.2017. 01003

Scheer, B. V., and Murray, A. (2011). Al Andalus ultra trail: an observation of medical interventions during a 219-km, 5-day ultramarathon stage race. Clin. J. Sport Med. 21, 444-446. doi: 10.1097/JSM.0b013e318225b0df

Scheer, B. V., Murray, D. A., Doral, M. N., and Karlsson, J. (2015). "Ultramarathon running injuries," in Sports Injuries, eds M. N. Doral and J. Karlsson (Berlin: Springer), 2889-2898. doi: 10.1007/978-3-642-36569-0_216

Scheer, B. V., Reljic, D., Murray, A., and Costa, R. J. S. (2014). The enemy of the feet: blisters in ultraendurance runners. J. Am. Podiatr. Med. Assoc. 104, 473-478. doi: $10.7547 / 0003-0538-104.5 .473$

Scheer, V. (2018). Participation trends of ultra endurance events. Sports Med. Arthrosc. Rev. (in press).

Scheer, V., Janssen, T. I., Vieluf, S., and Heitkamp, H.-C. (2018a). Predicting trail running performance with laboratory exercise tests and field based results. Int. J. Sports Physiol. Perform. doi: 10.1123/ijspp.2018-0390 [Epub ahead of print].

Scheer, V., Ramme, K., Reinsberger, C., and Heitkamp, H.-C. (2018b). VO2max testing in trail runners: is there a specific exercise test protocol? Int. J. Sports Med. 39, 456-461. doi: 10.1055/a-0577-4851

Schena, F., Pellegrini, B., Tarperi, C., Calabria, E., Salvagno, G. L., and Capelli, C. (2014). Running economy during a simulated 60-km trial. Int. J. Sports Physiol. Perform. 9, 604-609. doi: 10.1123/ijspp.2013-0302

Vernillo, G., Giandolini, M., Edwards, W. B., Morin, J.-B., Samozino, P., Horvais, N., et al. (2017a). Biomechanics and physiology of uphill and downhill running. Sports Med. 47, 615-629. doi: 10.1007/s40279-0160605-y

Vernillo, G., Millet, G. P., and Millet, G. Y. (2017b). Does the running economy really increase after ultra-marathons? Front. Physiol. 8:783. doi: 10.3389/fphys. 2017.00783

Vernillo, G., Savoldelli, A., Skafidas, S., Zignoli, A., La Torre, A., Pellegrini, B., et al. (2016). An extreme mountain ultra-marathon decreases the cost of uphill walking and running. Front. Physiol. 7:530. doi: 10.3389/fphys.2016. 00530

Vernillo, G., Savoldelli, A., Zignoli, A., Skafidas, S., Fornasiero, A., La Torre, A., et al. (2015). Energy cost and kinematics of level, uphill and downhill running: fatigue-induced changes after a mountain ultramarathon. J. Sports Sci. 33, 1998-2005. doi: 10.1080/02640414.2015.1022870

Vernillo, G., Savoldelli, A., Zignoli, A., Trabucchi, P., Pellegrini, B., Millet, G. P., et al. (2014). Influence of the world's most challenging mountain ultramarathon on energy cost and running mechanics. Eur. J. Appl. Physiol. 114, 929-939. doi: 10.1007/s00421-014-2824-y

Conflict of Interest Statement: The authors declare that the research was conducted in the absence of any commercial or financial relationships that could be construed as a potential conflict of interest.

Copyright () 2018 Scheer, Vieluf, Cramer, Jakobsmeyer and Heitkamp. This is an open-access article distributed under the terms of the Creative Commons Attribution License (CC BY). The use, distribution or reproduction in other forums is permitted, provided the original author(s) and the copyright owner(s) are credited and that the original publication in this journal is cited, in accordance with accepted academic practice. No use, distribution or reproduction is permitted which does not comply with these terms. 